\title{
OCR-THE 3 LAYERED APPROACH FOR CLASSIFICATION AND IDENTIFICATION OF TELUGU HAND WRITTEN MIXED CONSONANTS AND CONJUNCT CONSONANTS BY USING ADVANCED FUZZY LOGIC CONTROLLER
}

\author{
Dr.B.Rama and Santosh Kumar Henge \\ Department of Computer Science, Kakatiya University, Warangal, India \\ rama.abbidi@gmail.com, hingesanthosh@gmail.com
}

\begin{abstract}
Optical Character recognition is the method of digitalization of hand and type written or printed text into machine-encoded form and is superfluity of the various applications of envision of human's life. In present human life OCR has been successfully using in finance, legal, banking, health care and home need appliances. India is a multi cultural, literature and traditional scripted country. Telugu is the southern Indian language, it is a syllabic language, symbol script represents a complete syllable and formed with the conjunct mixed consonants in their representation. Recognition of mixed conjunct consonants is critical than the normal consonants, because of their variation in written strokes, conjunct maxing with pre and post level of consonants. This paper proposes the layered approach methodology to recognize the characters, conjunct consonants, mixed-conjunct consonants and expressed the efficient classification of the hand written and printed conjunct consonants. This paper implements the Advanced Fuzzy Logic system controller to take the text in the form of written or printed, collected the text images from the scanned file, digital camera, Processing the Image with Examine the high intensity of images based on the quality ration, Extract the image characters depends on the quality then check the character orientation and alignment then to check the character thickness, base and print ration. The input image characters can classify into the two ways, first way represents the normal consonants and the second way represents conjunct consonants. Digitalized image text divided into three layers, the middle layer represents normal consonants and the top and bottom layer represents mixed conjunct consonants. Here recognition process starts from middle layer, and then it continues to check the top and bottom layers. The recognition process treat as conjunct consonants when it can detect any symbolic characters in top and bottom layers of present base character otherwise treats as normal consonants. The post processing technique applied to all three layered characters. Post processing of the image: concentrated on the image text readability and compatibility, if the readability is not process then repeat the process again. In this recognition process includes slant correction, thinning, normalization, segmentation, feature extraction and classification. In the process of development of the algorithm the pre-processing, segmentation, character recognition and post-processing modules were discussed. The main objectives to the development of this paper are: To develop the classification, identification of deference prototyping for written and printed consonants, conjunct consonants and symbols based on 3 layered approaches with different measurable area by using fuzzy logic and to determine suitable features for handwritten character recognition.
\end{abstract}

David C. Wyld et al. (Eds) : CSITY, SIGPRO, AIFZ, NWCOM, DTMN, GRAPHHOC - 2016

pp. 75-88, 2016. (C) CS \& IT-CSCP 2016

DOI : $10.5121 /$ csit.2016.60407 


\section{KEYWORDS}

Optical Character Recognition (OCR), TopMiddleBottom Layer (TMBL) layer, BottomMiddleTop Layer (BMTL), Hand written and printed character recognition (HWPCR), Artificial Neural Network (ANN).

\section{INTRODUCTION}

Optical Character Recognition is the method of digitalization of hand and type written or printed text into machine-encoded form. OCR is the most active invention research area in the field of image processing, character and pattern recognition. In present life OCR has been successfully using in finance, legal, banking, health care and home need appliances. Character Recognition classified into two ways, online and offline. Online character and pattern recognition method is finer to their off mode counterparts in recognition of hand written characters due to the temporal information available with the formal information. In Off-Line mode character recognition, the written or printed document can be scanned as an image then it can be digitized then converted it into machine readable form with different character reorganization algorithmic methodology. Off-Line mode character recognition process is an active and effective research area towards to development of new innovations, ideas and techniques that would improve recognition accuracy. The OCR consists the different levels of processing methods like as Image Pre Acquisition, Acquisition, Pre-processing, Segmentation, Post processing, Feature Extraction and Classification. India is a multi cultural, literature and traditional scripted country. 18 official scripted languages are formed and have many local regional languages in India. Telugu is the official language of the southern Indian states of Telangana and Andhra Pradesh. Telugu is also spoken in all over in Malaysia, Bahrain, Oman, Singapore, Fiji, UAE and Mauritius. Officially, there are 10 numerals, 18 vowels, 36 consonants, and three dual symbols. Telugu is the Dravidian composed language and it is the third most popular script in India. The Telugu script is closely related to the Kannada script. In OCR, captured or scanned input image is active from number of stages like Image Acquisition, pre-processing, processing, post-processing, segmentation, feature extraction and classification to perform Optical Character Recognition. Scanned Images or captured photographs taken as input for the OCR system in Image Acquisition stage. Preprocessing is important and necessary to convert the raw data to correct deficiencies in the data acquisition process due to limitations of the capturing device sensor. Pre-processing stage step involves detect text stroke rate, binarization, normalization, noise removal and so on. Segmentation is the process of dividing the individual cum grouped characters, separating line spaces, words and mixed characters from scanned image. Feature extraction explores the exact identification of the characters, can be considered as finding a set of features that define the shape of the underlying character as precisely and uniquely as possible.

\section{EARLIER WORK WITH OPTICAL CHARACTER RECOGNITION ALGORITHMS}

In the past and present invasion of OCR, many algorithms are designed for different ways of character recognition processes such as Template Matching, Statistical Algorithm, Structural Algorithm, Neural Network Algorithm and Support Vector Machine. Template Matching Algorithm proposed only for the recognition of the typewritten characters. The Statistical Algorithm, Structural Algorithm, Neural Network Algorithm and Support Vector Machine proposed for recognition of both type and handwritten characters. Each algorithmic methodology carries both advantages and disadvantages. 


\subsection{Neural Network Algorithm}

An Artificial Neural Network is an innovative methodology for information processing. ANN is inspired by the biological nervous system, such as the main system act like as brain and its interconnected nerve process data. ANN composes huge number of inter-connected neurons for processing data cum elements working in harmony to solve the problems [25]. A neural network is a powerful data modelling tool that is able to capture and represent complex input/output relationships. Neural network algorithm activated and identifies the characters by boosting and worm-up of trained neuron of the neural network. Feed forward Neural Network, Feedback neural network and Self Organizing Map are the types of neural network. Neural network algorithm especially works for new characters can be found when it can middle of recognition process, and also it is a suitable.

\subsection{Support Vector Machine}

The Support Vector Machine (SVM) is a related to support vector networks and set of supervised learning methods used for classification. Support vector machine algorithm activated and discover the characters by scrutinise and mapping the given input information on with high priority dimensional future apace and it can be determine a dividing hyper plane with maximum and minimum margin data. SVM is robust, accurate and very effective even though when the training samples and models are less and it can perform good result without adding prior data sets and feed information.

\subsection{Structural Algorithm}

The initial idea behind the creation of structural algorithms is the recursive description of a complex pattern in terms of simpler patterns based on the size and shape of the object [23]. This structural algorithm activated and identifies by recognize compound component of the character. Structural algorithm classifies the input patterns on the basis of components of the characters and the relationship among these components. Firstly the primitives of the character are identified and then strings of the primitives are checked on the basis of pre-decided rules [00]. Structural pattern recognition is intuitively appealing because in addition to classification, this approach also provides a description of how the given path constructed from the primitives: [24]. Generally a character is represented as a production rules structure, whose left-hand side represents character labels and whose right-hand side represents string of primitives. The right-hand side of rules is compared to the string of primitives extracted from a word. So classifying a character means finding a path to a leaf: [22]. This algorithm mainly uses the structural shape pattern of the objects.

\subsection{Statistical Algorithm}

The purpose of the Statistical Algorithm is to determine and categorize the given pattern based on the statistical approach like as pre planned made observations, measurement approaches and a set of numbers prepared which is used to prepare a measurement vector [22]. Statistical algorithm uses the statistical decision functions and a set of optimality criteria which to maximizes the probability of the observed pattern given the model of a certain class.

Statistical algorithms activated and identifies by making the measurement and assumptions. Statistical algorithm is based on three assumptions. Such as distribution of present cum future set, sufficient statistics presented in each class and collection of pre-images to extract a set of features which represents each distinct class of image pattern. The major advantage is, it works even when prior data or information is not available about the characters in the training data. 


\subsection{Template Matching Algorithm}

Template Matching Algorithm known as pattern matching algorithm. All basic characters and symbols are pre-stored in the system, and it is system prototype that useful to classify, identifies the characters by comparing two pattern matching symbols or images. Template matching is the process of finding the location of sub image called a template inside an image. Template matching algorithm activated and identifies by Comparing derived image features and templates: [21]. It is easy to implements but it only works on the pre-stored fonts and templates.

\section{GENERAL POINTS OF ClaSSIFICATION OF THE CONSONANTS AND MIXED CONJUNCT CONSONANTS}

General points might be concentrated during the process of handwritten character recognition when digitized input image is, such as handwritten characters.

- Image clarity, quality and range of the pen ink plotted.

- Written text stroke, clarity, and thickness of the text.

- Pen or pencil ink injecting ratio on the paper.

- Local variations, rounded corners, and improper extrusions

- Unreflective and relative size of the character.

- Some characters represents different shapes

- In the translation point of view, it can be entirely or partly and it represents relative shift of the character.

- Individual and irrelative line pixels, segments and curves.

\section{GENERAL TELUGU CHARACTERS, NUMBERS AND SYMBOLS}

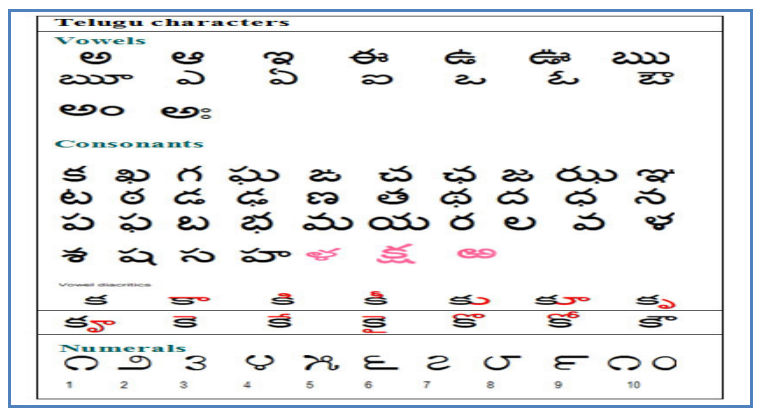

Figure 1. Telugu characters and numbers 
Computer Science \& Information Technology (CS \& IT)

\begin{tabular}{|c|c|c|c|c|c|c|c|c|c|c|c|c|c|c|c|c|}
\hline Snd. & $\mathbf{a}$ & $\overline{\mathbf{a}}$ & i & $\bar{T}$ & $\mathbf{u}$ & $\overline{\mathbf{u}}$ & ru & rū & e & $\overline{\mathbf{e}}$ & ai & o & $\overline{\mathbf{o}}$ & au & amp & ah \\
\hline Prim. & क & $\theta$ & 2 & $\theta_{\theta}$ & $\Leftrightarrow$ & $\Leftrightarrow$ & బ & 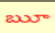 & ఎ & $\vdots$ & $\infty$ & a & $\varepsilon$ & ఔ & $\infty$ & అะ \\
\hline $\mathrm{Sec}$ & Inh. & $\infty$ & $\%$ & $0^{5}$ & o & or & ळ & ూ & \% & ङ & $q$ & $\infty$ & $\sigma^{6}$ & ా & ০ & ळ: \\
\hline$k$ & 5 & 5 & sి & s & su & కూ & 5 & కృ & s & st & ș & కా & $5^{6}$ & కౌ & 5o & 58 \\
\hline kh & ஓ & ఖా & क & $\$$ & ఖు & ఖూ & ฆృ & ఖూ & $\$ 3$ & $\Phi 5$ & क्3 & \$5 & कో & ఖౌ & ఖం & ఖ \\
\hline $\mathrm{g}$ & $x$ & $\pi$ & గ & ก์ & no & ño & Ђృ & గృ & $\pi$ & $\vec{n}$ & 조 & గా & గో & గా & no & Ks \\
\hline c & w & చా & చి & w & చు & చూ & చృ & చృ & $\overline{3}$ & చే & $\overline{3}$ & చా & చో & చౌ & చo & చః \\
\hline ch & $ఛ$ & चా & 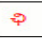 & ఛ & ఛు & ఛూ & ఛృ & ఛృ & $ఛ$ & ఛే & 포 & ఛా & $\Psi^{6}$ & ఛా & ఛం & ఛะ \\
\hline$t$ & $\omega$ & er & es & $e^{5}$ & ew & టూ & టృ & ట్లా & $\overline{3}$ & $\overrightarrow{3}$ & बై & eా & $e^{6}$ & అా & $\omega$ & $\omega$ \\
\hline th & ఠ & $\sigma$ & 8 & 8 & ఠు & ఠూ & ఠృ & ఠూ & $\overline{0}$ & ฮే & 혼 & ఠా & $\delta^{6}$ & ఠా & ఠం & ఠః \\
\hline d & $\epsilon$ & $\infty$ & a & \& & డు & డూ & ઢ) & డృ & $a$ & $\overline{\mathrm{b}}$ & $\bar{z}$ & డా & $6^{6}$ & ढా & డం & డs \\
\hline dh & $\zeta$ & दा & दิ & द & दు & दూ & ६) & ఢా & द & दे & $\bar{q}$ & ఢా & $\varphi^{\circ}$ & दా & ६0 & ६8 \\
\hline$n$ & $\varepsilon$ & हా & ణรి & ణรీ & Eు & हూం & ణృ & ణృ & $\bar{\varepsilon}$ & $\overrightarrow{ह 5}$ & घुㄹㄹ & हూ & ह5 & ణా & ణం & हః \\
\hline$t$ & बs & उా & 3 & 3 & తు & తూ & తృ & తూ & उె & बే & e3․ & తా & తో & తా & తం & తః \\
\hline th & $\Phi$ & क् & $\Phi$ & $\Phi$ & థు & థా & థృ & థృ & $\bar{\Phi}$ & $\vec{\Phi}$ & $\Phi$ & థా & $\Phi^{6}$ & థా & фо & థะ \\
\hline d & $\sigma$ & $\omega$ & Q & Q & దు & దూ & దృ & దృ & $\bar{b}$ & దే & $\bar{\alpha}$ & దా & $ద^{6}$ & దౌ & దం & దః \\
\hline dh & $\phi$ & पా & $\varnothing$ & 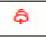 & ధు & ధూ & ధృ & ధ్రా & $\overline{\mathbf{Q}}$ & ดే & $\bar{\Phi}$ & ధా & $\bar{\varphi}^{6}$ & दౌ & фо & ధะ \\
\hline$n$ & న & నా & ని & నీ & ను & నూ & వృ & నృ & నె & నే & నై & నా & $5^{6}$ & నౌ & నం & నః \\
\hline b & $\approx$ & एా & 28 & 25ి & 20 & ణూ & బృ & జృ & బె & బే & खై & బా & 256 & బౌ & ஓం & బะ \\
\hline bh & ६ & భా & दి & ६కి & భు & భూ & భృ & భూ & భె & భే & ఖై & భొ & दో & ६ౌ & ६ం & ६ః \\
\hline$r$ & $\sigma$ & $\sigma$ & 8 & 8 & రు & రూ & రృ & రూ & $\overline{0}$ & ठี & 호 & $\delta^{\circ}$ & $5^{6}$ & రా & రం & రః \\
\hline 1 & 0 & er & 0 & $\delta$ & $\infty 0$ & er & లృ & లూ & बु & $\overrightarrow{0}$ & 를 & లా & $\sigma^{6}$ & లా & 00 & 0ะ \\
\hline I & $\$$ & $\infty$ & 8 & 8 & తు & ๘ూ & ১ & హా & 3 & a & ख & ా & 5 & अ & $\infty$ & 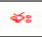 \\
\hline ś & శ & ซా & 8 & 항 & శు & శూ & శ) & శూ & z & है & ż & శా & $\overbrace{}^{6}$ & శౌ & శం & శః \\
\hline ksh & క & 5 & కి & క్ & క్ & కూ & 5 & 55 & इ & ईई & s. & కొ & క్షో & కू & క్ & కః \\
\hline$r$ & $\infty$ & er & e3 & क & ex & ear & एృ & ట్రా & $\bar{\omega}$ & $\overrightarrow{\mathrm{e}}$ & बై & eా & $\mathrm{eS}^{6}$ & eృౌ & $\infty \infty$ & ess \\
\hline
\end{tabular}

Figure 2. Combinational vowels with consonants

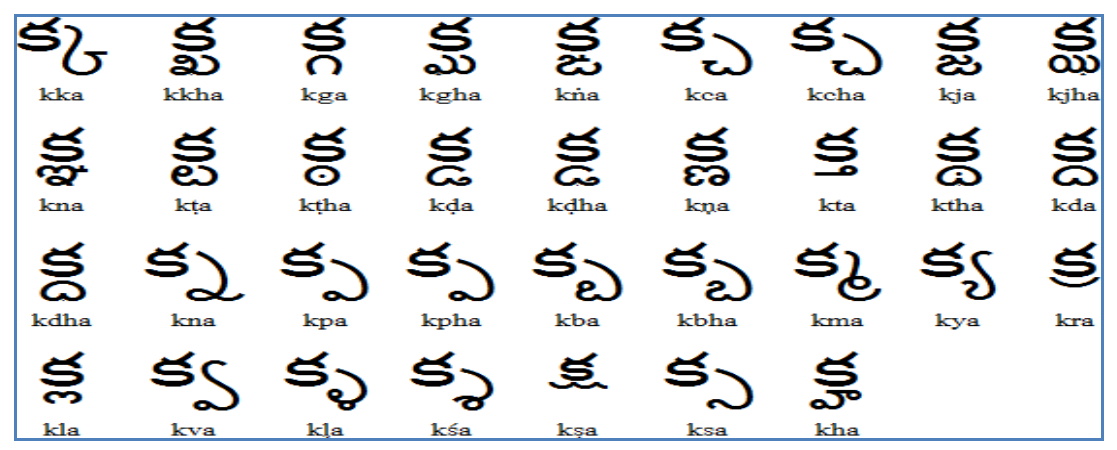

Figure 3. Conjunct consonants

\section{PAPER OBJECTIVES}

The main objectives of this paper is To determine suitable features for decision making state and identification of Telugu Written and Printed Consonants and Conjunct Consonants based on 3 layer approach with their orientation, alignment method. And also to develop the identification, classification and deference prototyping for written and printed mixed and conjunct Consonants characters with their orientation, alignment method by using fuzzy logic system.

\section{WORKING METHODOLOGY}

The scanned image page contains the different stroke levels of consonants, normal and mixed conjunct consonants. In this research paper we are concentrated on different stroke levels of 
consonants and mixed conjunct consonants. The scanned image has been processed under the following processes.

- Hand written Text in image identification and detection.

- Hand written Text layout or orientation identification.

- Text classification of the text based on the orientation of the text

- Segmentation.

- Character processing applying the Gaussian Fuzzy process

- Post Processing Analysis.

In this implementation Fuzzy logic based neural network having the four methods (input, fuzzification, inference and defuzzification) have been used. Fuzzification is the scaling of input data to the universe of discourse (the range of possible values assigned to fuzzy sets). Rule application is the evaluation of fuzzified input data against the fuzzy rules written specifically for the system. Defuzzification is the generation of a specific output value based on the rule strengths that emerge from the rule application. The Fuzzy based neural network rules can be applied for the paper front and back side layered written and printed characters.

This paper implements the aadvanced ffuzzy llogic system controller collected the text in the form of written or printed, collected the text images from the scanned file, digital camera, Processing the Image with examine the high intensity of images based on the quality ration, extract the image characters depends on the quality then check the character orientation and alignment then to check the character thickness, base and print ration. The input image characters can classify into the two ways, first as normal consonants and second as conjunct consonants, first way represents the normal consonants and the second way represents conjunct consonants. In this research, we classify input image written and printed as normal consonants and second as conjunct consonants based on the 3 layer approach. The middle layer represents normal consonants and the top and bottom layer represents conjunct consonants. Here recognition process starts from middle layer, and then it will check the top and bottom layers, the recognition process treat as conjunct consonants when it can detect any symbolic characters in top and bottom layers of present base character otherwise treats as normal consonants as shown in the fig.5.

Capture the entire consonant or conjunct consonant characters from 3 layers Middle, Top, Bottom(MTB) into single character or symbol. After conversion it into single symbolic character, then the concern algorithmic methodology can be applied to identify the realistic name of the character. In this methodology to classify the consonants and conjunct consonants proposed concern algorithmic methodology can be applied in second level.

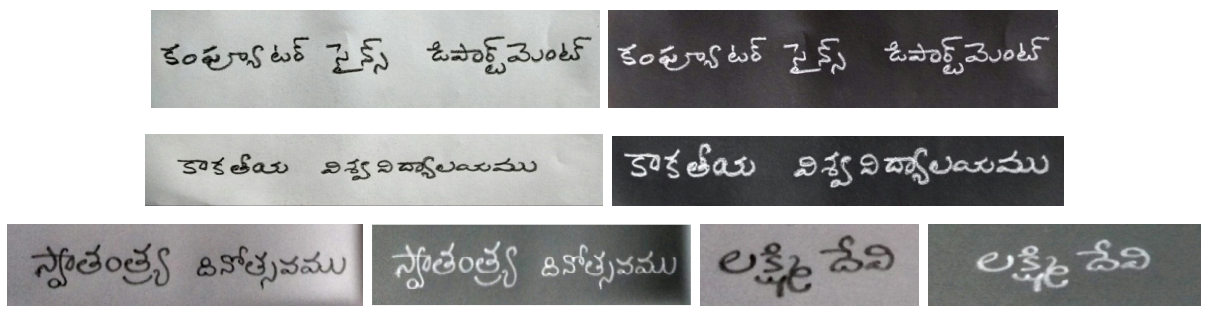

Figure 4. Examples and Tested Samples of handwritten Telugu characters with different modes. 

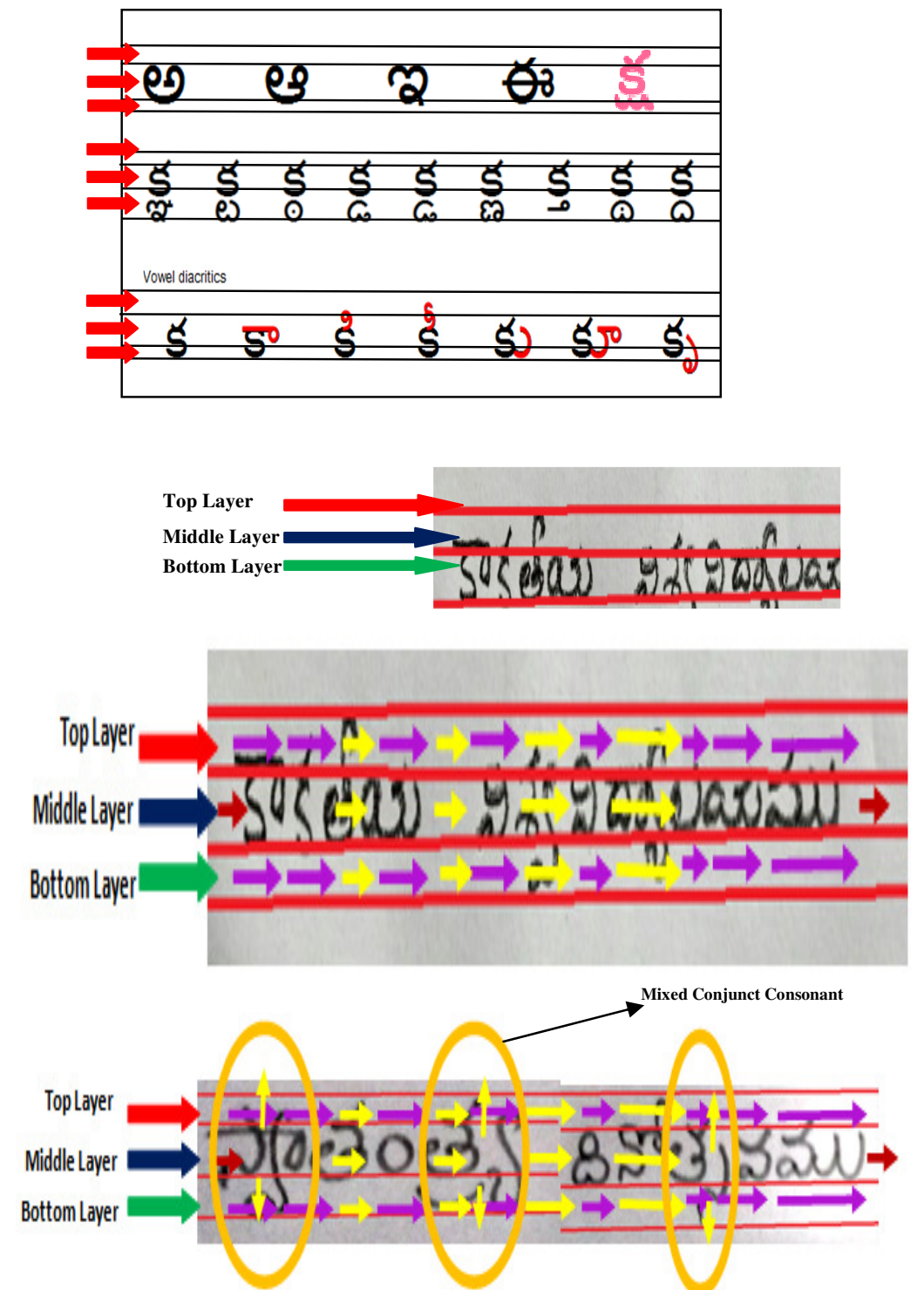

Figure 5. Tested Samples of handwritten Telugu characters with layers to help the sensor to detect variation of the written character type.

We are applied the post processing technique to all 3 layer characters. Then after in Post processing of the image, we are concentrated on the Image text readability and compatibility. If the readability is not process then repeat the process again as shown data flow structure fig.6. In this recognition process includes slant correction, thinning, normalization, segmentation, feature extraction and classification. 


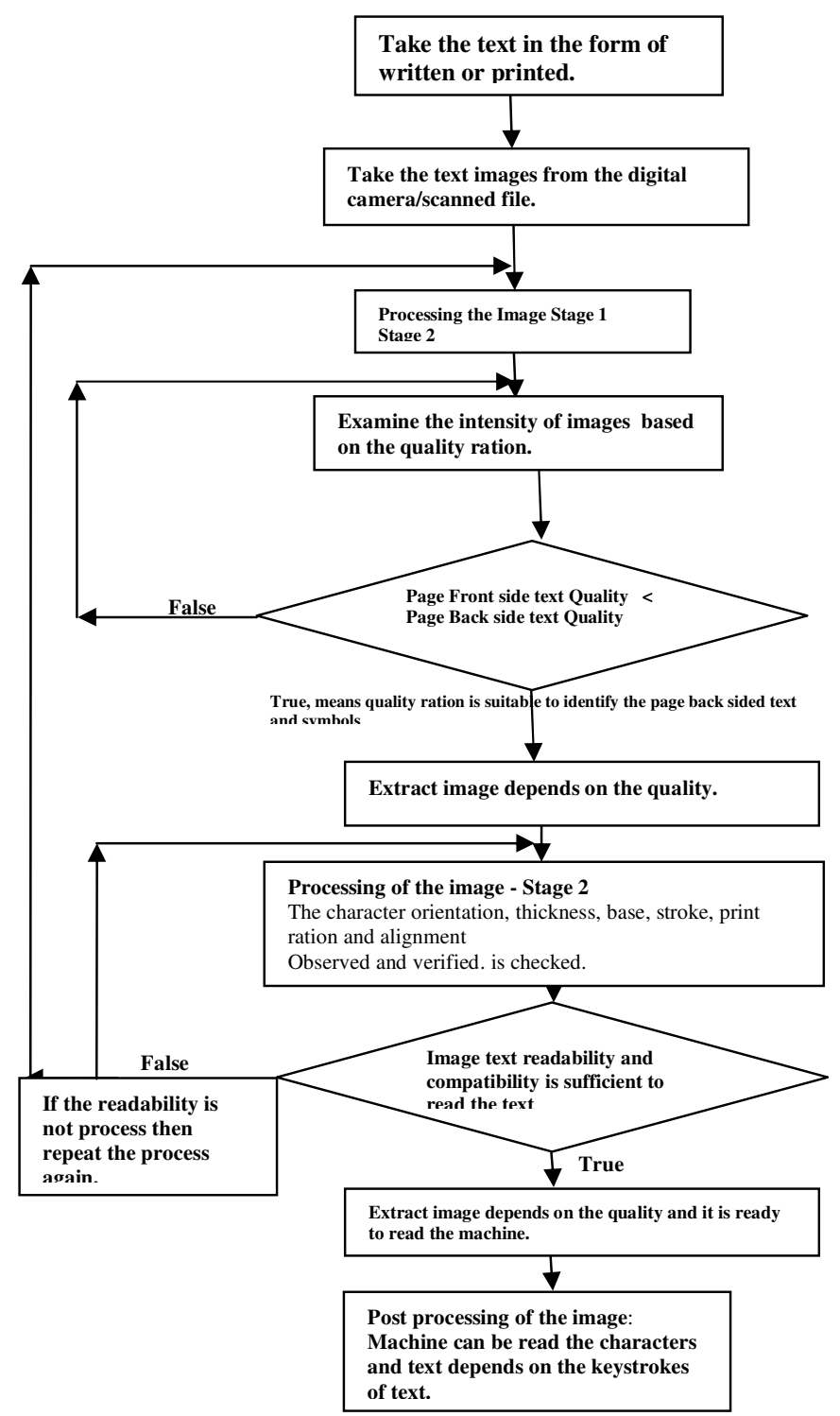

Figure 6. Data Process and next level flow diagram in OCR process.

In the process of development of the algorithm the pre-processing, segmentation, character recognition and post-processing modules were discussed. The main objectives to the development of this paper are: To develop the classification, identification of deference prototyping for Written and Printed Consonants, Conjunct Consonants and symbols based on 3 layer approach with different measurable area by using fuzzy logic and to determine suitable features for handwritten character recognition.

\section{IMPLEMENTATION}

The Fuzzy logic was for the most part an object of skepticism and derision, in part because the word "fuzzy" is generally used in a pejorative sense. Fuzzy logic is not fuzzy. Basically, fuzzy logic is a precise logic of imprecision and approximate reasoning. More specifically, fuzzy logic may be viewed as an attempt at formalization/mechanization of two remarkable human 
capabilities. First, the capability to converse, reason and make rational decisions in an environment of imprecision, uncertainty, incompleteness of information, conflicting information, partiality of truth and partiality of possibility - in short, in an environment of imperfect information. And second, the capability to perform a wide variety of physical and mental tasks without any measurements and any computations [1].

The three elements required to realize a fuzzy system are fuzzification, rule application, and defuzzification. Fuzzification is the scaling of input data to the universe of discourse (the range of possible values assigned to fuzzy sets). Rule application is the evaluation of fuzzified input data against the fuzzy rules written specifically for the system. Defuzzification is the generation of a specific output value based on the rule strengths that emerge from the rule application.

In a realized fuzzy system, a microcontroller or other engine runs a linked section of object code that consists of two segments. One segment implements the fuzzy logic algorithm, performing fuzzification, rule evaluation, and defuzzification, and thus can be thought of as a generic fuzzy logic inference engine. The other segment ties the expected fuzzy logic inputs and outputs, as well as application-specific fuzzy rules, to the fuzzy logic inference engine[1] as shown in the Figure 7.

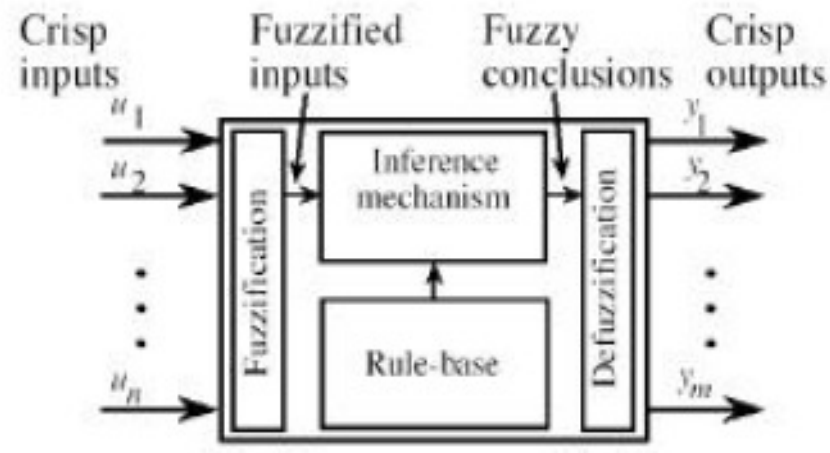

Figure 7. Basic block diagram of Fuzzy System Crisp inputs and Outputs.

One may ask where and how fuzzy logic is implemented. here with the layer quadrants location and three layered quadrants differentiation method for consonants and conjunct consonants with the set of rules are known and which are the feeds for fuzzy logic controller [8 - 9] fuzzification rules, these cases and conditions would be implemented as the if cases and for each individual quadrant the processing action is to be done is written as the then-corresponding action Fuzzyneural network having the four layers (input, fuzzification, inference and defuzzification) have been used.

\subsection{Basic Configuration of a Fuzzy System}

Fuzzy controller in a closed-loop configuration (top panel) consists of dynamic filters and a static map (middle panel). The static map is formed by the knowledge base, inference mechanism and fuzzification and defuzzification interfaces. 


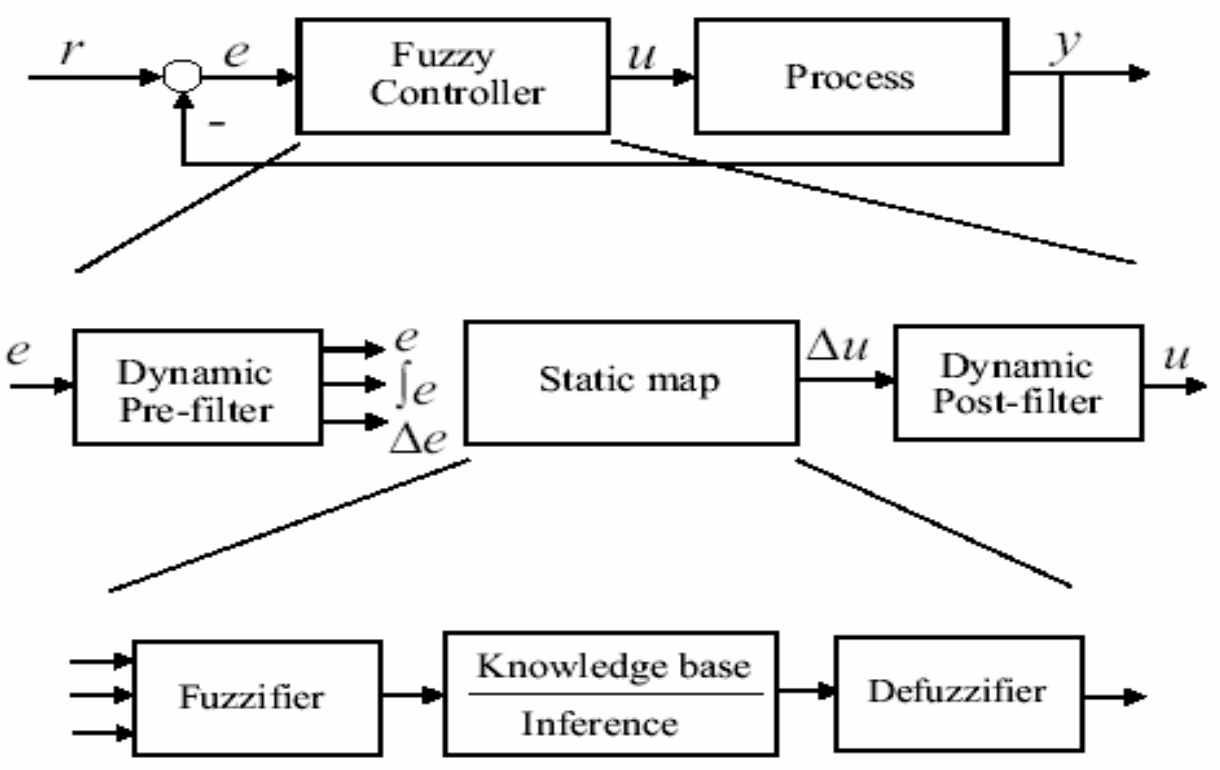

Figure 8. Fuzzy controller in a closed-loop configuration (top panel) consists of dynamic filters and a static map (middle panel). The static map is formed by the knowledge base, inference mechanism and fuzzification and defuzzification interfaces.

\subsection{Fuzzy Sets}

Fuzzy sets can be effectively used to represent linguistic values, such as low, young, and complex. A fuzzy set can be defined mathematically by assigning to each possible individual in the universe of discourse a value representing its grade of membership in the fuzzy set to a greater or lesser degree as indicated by a larger or smaller membership grade. The fuzzy set is represented as where $\mathrm{x}$ is an element in $\mathrm{X}$ and $\mu \mathrm{A}(\mathrm{x})$ is a membership function of set $\mathrm{A}$ which defines the membership of fuzzy set $\mathrm{A}$ in the universe of discourse, $\mathrm{X}$.

\subsection{Fuzzy Membership Functions}

A fuzzy set is characterized by a membership function which associates with each point in the fuzzy set a real number in the interval $[0,1]$, called degree or grade of membership. The membership function may be triangular, trapezoidal, Gaussian etc. A triangular membership is described by a triplet $(\mathrm{a}, \mathrm{m}, \mathrm{b})$, where , $\mathrm{m}^{c e}$ is the modal value, , $\mathrm{a}^{\text {ee }}$ and , , $\mathrm{b}^{\text {ce }}$ are the right and left boundary respectively. The trapezoidal membership function (shown in Figure. 9) is defined as follows. 


$$
\mu_{z}\left(x_{k}, y_{k}\right)=\left\{\begin{array}{cl}
1 & x_{k} \in\left[u_{k}, U_{k}\right] \\
1-\max \left(0, \min \left(1, \gamma_{k}\left(u_{k}-x_{k}\right)\right)\right) & x_{k} \prec u_{k} \\
1-\max \left(0, \min \left(1, \gamma_{k}\left(x_{k}-U_{k}\right)\right)\right) & x_{k}>U_{k}
\end{array}\right.
$$

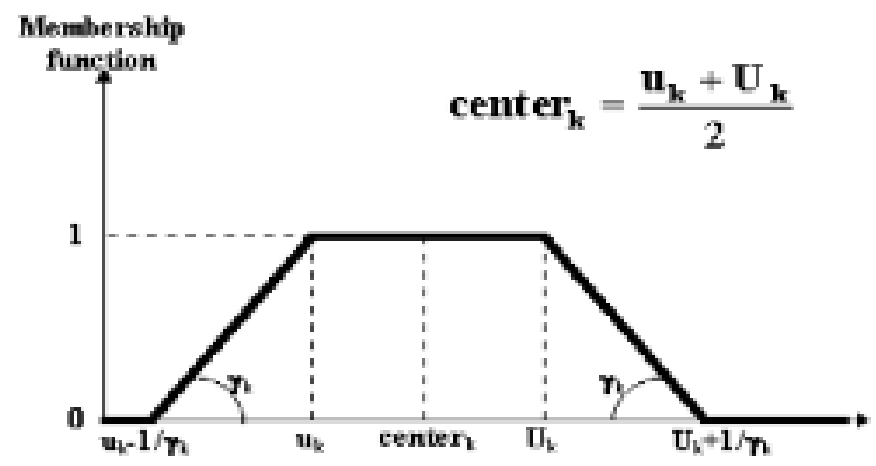

Figure 9. Trapezoidal Membership

Function for $\mu \mathrm{Z}(\mathrm{xk}, \gamma \mathrm{k})$

Another fuzzy membership function that is often used to represent vague, linguistic terms is the Gaussian which is called Gaussian membership function (shown in figure 10) is defined as follows.

$$
\begin{gathered}
L_{Z}\left(x_{k}, \gamma_{k}\right)=\exp \left(-\frac{1}{2} \cdot \frac{\left(x_{k}-\operatorname{conter}_{k}\right)^{2}}{\gamma_{k}{ }^{2}}\right) \\
\text { center }{ }_{k}=\frac{u_{k}+U_{k}}{2} \\
\text { with } \gamma=0 \text { for any } k \in\{1,2, \ldots, n\}
\end{gathered}
$$

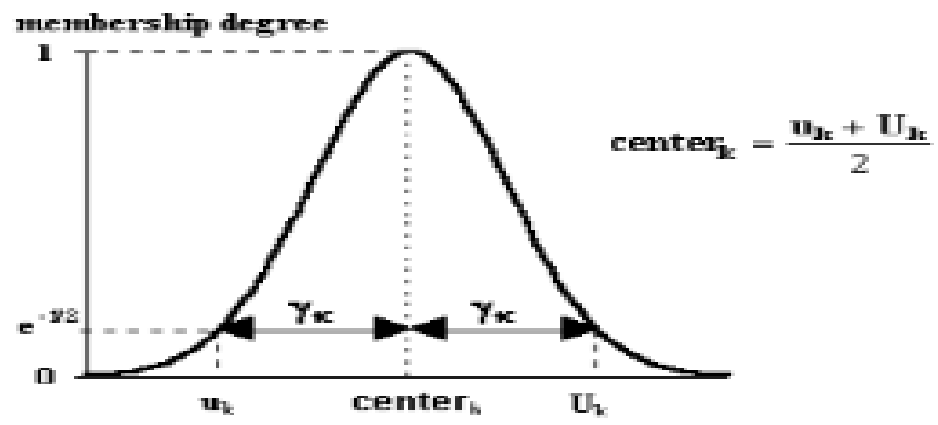

Figure 10. Gaussian Membership Function for $\mu \mathrm{Z}(\mathrm{xk}, \gamma \mathrm{k})$

\subsection{Gaussian Bell curve sets}

Give richer fuzzy system with simple learning laws that tune the bell curve variance. The Gaussian Function is represented by "(equation 1)," 


$$
\mu_{A_{i}}\langle x\rangle=\text { Gaussian }\left\langle x, c_{i}, \sigma_{i}\right\rangle=e^{-\left(x-c_{i}\right)^{2} / 2 \sigma_{i}^{2}}
$$

Where $\mathrm{Ci}$ is the center of the $\mathrm{i}^{\text {th }}$ fuzzy set and $\sigma_{\mathrm{i}}$ is the width of the $\mathrm{i}^{\text {th }}$ fuzzy set.

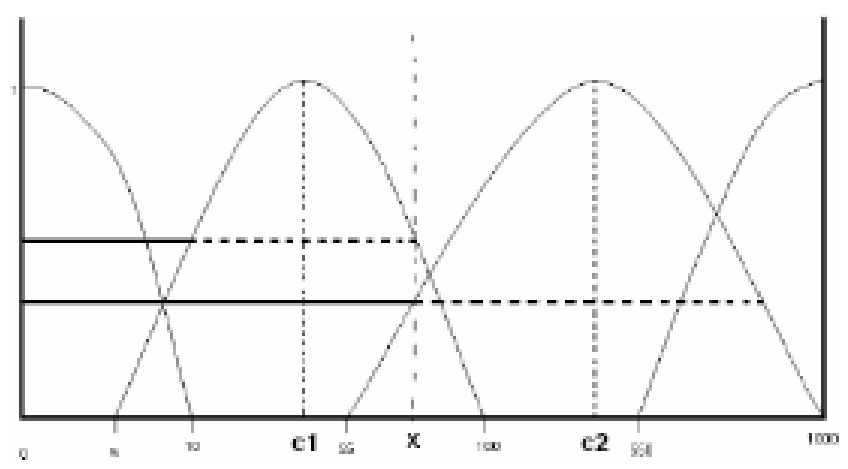

Figure 11. Representation of DATA Cost driver using Gaussian Membership Function

We define a fuzzy set for each linguistic value with a Gaussian shaped membership function $\mu$ is shown in Figure 10. We have defined the fuzzy sets corresponding to the various associated linguistic values for each variable / parameter of interest it may be character intensity, orientation, layout or anything.

In this research, a new fuzzy effort estimation model is proposed by using Gaussian function to deal with linguistic data or text image with three layered quadrant position analysis, and to generate fuzzy membership functions and rules for further processing the membership functions Primitives have been added to find form a character, which is part of the lexicon. The word is not said to be recognized till it is tested with lexicon containing root words with an efficient algorithm [7]. The system working model is designed as shown in the flowchart figure 6, and the process the recognition the consonants and conjunct consonants based the figure 8, figure 9, figure. 10 and figure. 11 is repeated till the whole text is reached to get the clarity and in readable and understandable.

\section{DISCUSSION}

The proposed algorithmic data flow presented to get the versatility in implementation while constructing an OCR system; our proposal system can scan the text in different layered approach with their different directions and orientation. There are many advantages of the proposed system. First, when there are some feature parts which are related to knowing the decision making stages and identification of mixed hand written letters and consonant character and the Second, identification of low rate and low quality written mixed conjunct consonant text.

\section{FUTURE SCOPE}

The proposed 3 layered methodology approach planning to test and it can be implementing either using the math tool or the LabVIEW VI GUI and MathLab. Our future work aims to improve the classifier of the mixed and non-mixed conjunct consonants to achieve still better recognition rate with our future proposal algorithmic methodology and also to improve the better recognition procedure for low quality readable imaged Telugu mixed-conjunct-consonants. 


\section{ACKNOWLEDGEMENTS}

I Dr B.Rama would like to thank everyone.

I Mr Santosh Kumar Henge would like to thank everyone.

\section{REFERENCES}

[1] Lotfi A. Zadeh.: Is there a need for fuzzy logic? Department of EECS, University of California, Berkeley, CA 94720- 1776, United States, 8 February 2008; 25 February 2008.

[2] H. Swethalakshmi, Anitha Jayaraman, V. Srinivasa Chakravarthy, C. ChandraSekhar, : Online Handwritten Character Recognition of Devanagari and Telugu Characters using Support Vector Machines, Department of Computer Science and Engineering, Department of Biotechnology, Indian Institute of Technology Madras, Chennai - 600 036, India.

[3] RAZALI BIN ABU BAKAR,: Development of Online Unconstrained Handwritten Character Recognition Using Fuzzy Logic, Universiti Teknologi MARA.

[4] Fuzzy Logic Toolbox User's Guide, The MathWorks Inc., 2001.

[5] Santosh Kumar Henge, Laxmikanth Ramakrishna, Niranjan Srivastava,: Advanced Fuzzy Logic controller based Mirror- Image-Character-Recognition OCR, The Libyan Arab International Conference on Electrical and Electronic 3101/01/32-32 Engineering LAICEEE. 3101/01/32-32. Pg $261-268$.

[6] P.Vanaja Ranjan,: Efficient Zone Based Feature Extration Algorithm for Hand Written Numeral Recognition of Four Popular South Indian Scripts, Journal of Theoretical and Applied Information Technology. pg 1171-1181.

[7] RAZALI BIN ABU BAKAR,: Development of Online Unconstrained Handwritten Character Recognition Using Fuzzy Logic, Universiti Teknologi MARA.

[8] P. Phokharatkul, K. Sankhuangaw, S. Somkuarnpanit, S. Phaiboon, and C. Kimpan: Off-Line Hand Written Thai Character Recognition using Ant-Miner Algorithm. World Academy of Science, Engineering and Technology, 8, 2005, Pg 276-281.

[9] Mr.Danish Nadeem \& Miss.Saleha Rizvi,: Character Recognition using Template Matching. DEPARTMENT OF COMPUTER SCIENCE, JAMIA MILLIA ISLAMIA NEW DELHI-25.

[10] Ch. Satyananda Reddy, KVSVN Raju,: An Improved Fuzzy Approach for COCOMO"e Effort Estimation using Gaussian Membership Function JOURNAL OF SOFTWARE, VOL. 4, NO. 5, JULY 2009, pp 452-459.

[11] L.A. Zadeh,: Outline of a new approach to the analysis of complex systems and decision processes, IEEE Transaction on Systems Man and Cybernetics SMC-3 (1973) 28-44.

[12] L.A. Zadeh,: Generalized theory of uncertainty(GTU)-principal concepts and ideas, Computational Statistics \& Data Analysis 51 (2006) 15-46.

[13] L.A. Zadeh,: On the analysis of large scale systems, in: H. Gottinger (Ed.), Systems Approaches and Environment Problems, Vandenhoeck and Ruprecht, Gottingen, 1974,pp. 23-37.

[14] L.A. Zadeh,: A fuzzy-algorithmic approach to the definition of complex or imprecise concepts, International Journal of Man-Machine Studies 8 (1976) 249-291.

[15] L.A. Zadeh,: From imprecise to granular probabilities, Fuzzy Sets and Systems 154 (2005) 370-374. 
[16] L.A. Zadeh,: Toward a perception-based theory of probabilistic reasoning with imprecise probabilities, Journal of Statistical Planning and Inference 105 (2002) 233-264.

[17] I. Perfilieva,: Fuzzy transforms: a challenge to conventional transforms, in: P.W. Hawkes (Ed.), Advances in Images and Electron Physics, vol.147, Elsevier Academic Press, San Diego 2007, pp.137-196.

[18] A.P. Dempster,: Upper and lower probabilities induced by a multivalued mapping, Annals of Mathematical Statistics 38 (1967) 325-329.

[19] G. Shafer,: A Mathematical Theory of Evidence, Princeton University Press, Princeton, NJ, 1976

[20] D. Schum,: Evidential Foundations of Probabilistic Reasoning, Wiley \& Sons, 1.

[21] Purna Vithlani, Dr. C. K. Kumbharana, : A Study of Optical Character Patterns identified by the different OCR Algorithms, International Journal of Scientific and Research Publications, Volume 5, Issue 3, ISSN 2250-3153 March 2015.

[22] Rohit Verma and Dr. Jahid Ali, : A-Survey of Feature Extraction and Classification Techniques in OCR Systems, International Journal of Computer Applications \& Information Technology, Vol. 1, Issue 3, November 2012.

[23] Richa Goswami and O.P. Sharma, : A Review on Character Recognition Techniques, IJCA, Vol. 83, No. 7, December 2013.

[24] Ms.M.Shalini, Dr.B.Indira, : Automatic Character Recognition of Indian Languages - A brief Survey, IJISET, Vol. 1, Issue 2, April 2014.

[25] José C. Principe, Neil R. Euliano, Curt W. Lefebvre: Neural and Adaptive Systems: Fundamentals Through Simulations", ISBN 0-471-35167

\section{AUTHORS}

Dr B.RAMA, She received her Ph.D. Degree in Computer Science from Padmavati Mahila Visvavidyalayam (Padmavati Women's University), Thirupathi-India in the year of 2009. She is working as Assistant Professor in Computer Science since six years at Department of Computer Science, University Campus College, Kakatiya University. She was the Chairperson, Board of Studies in Computer Science from 2013-15. She is having total 11 years of Teaching Experience in Engineering Colleges. She is author or co-author around 20 scientific papers mainly in IEEE international Conferences and International Journals. Her area of interest is Artificial Intelligence and Data Mining.

SANTHOSH KUMAR HENGE, He received his M.Phil. Degree in Computer Science from Periyar University, Salem - presently he is working as Associate Professor in Computer Science. He is having very good International level teaching experience. Previously, He worked in various countries Maldives, Libya, Oman and Ethiopia with different level of positions. He was published more than 16 research papers in International Journals and Conference Proceedings. He is doing his research in the field of Artificial Intelligence-Neuro based Fuzzy System. His area of interest is Artificial Intelligence and Data Mining.
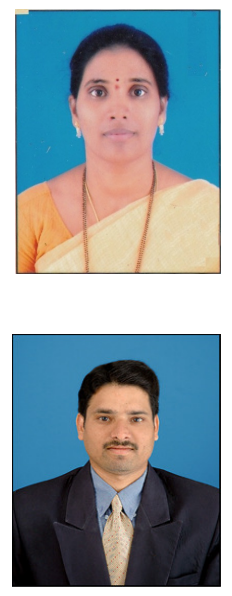